Centre for Reproductive Medicine, Centre for Prenatal Diagnosis, First Hospital, Jilin University, Changchun, China.

Financial support: Youth Foundation of First Hospital, Jilin University (00400050032)

Competing interests: The authors declare that they have no competing interests.

Received: Oct 6, 2016 Accepted: Jan 3, 2017

Corresponding Author: Ruizhi Liu

Centre for Reproductive Medicine, Centre for Prenatal Diagnosis, First Hospital, Jilin University, No. 71 Xinmin Street, Changchun 130021, Jilin, China.

Tel: 0086-0431-85654528 Fax: 0086-0431-85654528 Irz410@126.com

\section{Live birth after transfer of vitrified-warmed embryo derived from vitrified-warmed oocyte and frozen-thawed sperm following failed ICSI. Case report}

\author{
ZHIHONG ZHANG, JIHONG ZHU, HONGYANG ZHANG, QI XI, \\ DONGFENG GENG, SHU DENG, RUIZHI LIU
}

\begin{abstract}
Since the first successful pregnancy from a frozen human oocyte was reported, remarkable technological progress has been made in the area of cryopreservation of human oocytes. We report a successful delivery of two healthy babies after transfer of vitrified-warmed embryos derived from intracytoplasmic sperm injection (ICSI) with vitrified-warmed oocytes and frozen-thawed sperm. A female patient and her husband with severe oligoasthenspermia are reported. At the day of oocyte collection, very few inactive sperms were found in her husband semen. Multiple site open testicular biopsy was performed on her husband, but no sperm was retrieved. The patient did not become pregnant after transferring two embryos coming from half of oocytes and inactive sperms. The patient got pregnant and delivered two healthy babies after receiving a transfer of vitrified-warmed embryos from vitrified-warmed oocytes and frozen-thawed sperm.

(Rev Med Chile 2017; 145: 402-405)
\end{abstract}

Key words: Embryo Implantation, Delayed; Embryo Transfer; Semen Preservation.

\section{Embarazo a partir de un embrión vitrificado derivado de oocitos vitrificados y espermios descongelados. Reporte de un caso}

La criopreservación de oocitos humanos ha progresado mucho desde que el primer embarazo exitoso desde un oocito congelado fue informado. Nosotros informamos el parto de dos bebés sanos después de transferir embriones vitrificados y recalentados y espermios descongelados. Se trata de una mujer y su marido con una oligoastenoespermia severa. En el día de la recolección de oocitos, se encontraron muy pocos espermios inactivos en el semen del marido. Se tomaron biopsias testiculares pero se encontraron muy pocos espermios inactivos. La mujer logró quedar embarazada y dio luz a dos bebés sanos después de recibir una trasferencia de embriones vitrificados y recalentados, y de espermios descongelados. 
A ssisted reproductive technology (ART) has been advancing rapidly, and patients with clinically difficult characteristics can be successfully treated. Unfertilized oocyte cryopreservation, one of the advancing techniques of ART, has been established. The survival rate after thawing still needed to be improved.

Recently, the freezing method has been changing from slow cooling cryopreservation to ultra rapid cryopreservation, namely, vitrification. This technique assures a high survival rate ${ }^{1,2}$ and is being used for cryopreservation of oocytes and embryos as a clinical application more and more. The fertility of survivors who underwent cancer treatments such as chemotherapy, radiotherapy and bone marrow transplantation has been impaired by the treatments. Thus, it is imperative to reserve these cancer survivors' fertility before cancer treatments by cryopreserving their ovaries, oocytes or embryos ${ }^{3,4}$. Oocyte cryopreservation, however, may also be appropriate in circumstances where embryo freezing is not possible e.g in cases of malignant disease in young women where the imminent cytotoxic therapy is likely to inhibit subsequent oocyte development and where there is no male partner or in cases of routine in vitro fertilization (IVF) when no sperm are retrieved. The efficiency and success of subsequent use of frozen oocytes in such cases will, inevitably, be dependent on factors including the ability to select embryos for transfer. Patients with oligozoospermia may benefit from intracytoplasmic sperm injection (ICSI) treatment. However, some of infertile couples face poor results after ICSI and subsequently use donor sperm.

In the present study, we report the healthy outcome of two girls who were born after transfer of two vitrified-warmed embryos produced by ICSI using vitrified-warmed oocytes and frozen-thawed donor sperms.

\section{Case presentation}

The patient was a 27-year-old woman. Her husband had been diagnosed with severe oligoasthenspermia. Ovarian stimulation was achieved by the daily administration of recombinant FSH (150 IU/day) following pituitary desensitisation with GnRH agonist. Meiotic maturation of preovulatory oocytes was induced by administration of human chorionic gonadotrophin (hCG; 6,000 IU) and cumulus-oocyte complexes were retrieved transvaginally $36 \mathrm{~h}$ later under ultrasound guidance. Twenty-five oocyte-cumulus complexes were identified in the aspirated follicular fluid. About ten inactive sperms were found in her husband semen. Multiple site open testicular biopsy was performed on her partner on the day of oocyte collection but no sperm was retrieved. The couple opted to select half of oocytes to be fertilized and have the twelve mature oocytes cryopreserved pending a decision on future treatment. Following digestion of cumulus-oocyte complexes using hyaluronidase $(10 \mathrm{IU} / \mathrm{ml}), 23$ of the 25 oocytes were confirmed as being at the metaphase II stage of meiosis and 11 mature oocytes were used to intracytoplasmic sperm injection (ICSI) and other 12 of them were prepared for cryopreservation. Other oocytes were frozen $4 \mathrm{~h}$ after follicle aspiration and were stored in 2013 and remained in storage for five months prior to thawing. Two had 2 visible pronuclei at $17 \mathrm{~h}$ post insemination (hpi) after intracytoplasmic sperm injection by using the only about ten inactive sperms from her husband. On day-3 post-ICSI, the embryos in culture included two 6-cell embryos with $<20 \%$ fragmentation and were transferred. Pregnancy was not achieved after 14 days of embryos' transfer.

Straws containing cryopreserved oocytes were thawed rapidly. All 12 cryopreserved ooctyes were thawed, and 12 oocytes survived the thaw process. Cryopreserved donor sperm was prepared by density gradient centrifugation and intracytoplasmic sperm injection. Post injection oocytes were cultured in Quinn's Advantage Fertilisation medium for $17 \mathrm{~h}$ and assessed for the presence of pronuclei before being transferred to Quinn's Advantage Cleavage medium. Twelve oocytes underwent ICSI and 9 were successfully fertilized with 2 visible pronuclei. Timing of syngamy was assessed at $23 \mathrm{hpi}$ and embryo development was assessed at $41 \mathrm{hpi}$ prior to selection for cryopreservation. Consequently, on December 26th, 2013, two vitrified-warmed cleavage embryos (Gardner's criteria, 6 II and 6 II) were transferred to the patient, and two gestational sacs with fetal heart movements were observed by ultrasonography at eight weeks of gestation. Finally, this resulted in a birth of two normal healthy female, weighing 4,700 g and $4,000 \mathrm{~g}$ at 35 weeks of gestation by cesarean delivery on October $25^{\text {th }}, 2014$. The twins were all healthy after two years. 


\section{Discussion}

Cryopreservation of human oocytes has long been postulated to be a potentially useful addition to the range of techniques available in assisted reproduction laboratories. It would permit the storage of reproductive potential for women at risk of loss of fertility when undergoing cytotoxic therapy, allow storage of oocytes when sperm retrieval is not possible in a cycle of IVF treatment. Oocyte cryopreservation offers more advantages compared to embryo freezing, such as fertility preservation in women at risk of losing fertility due to oncological treatment or chronic disease, egg donation, and postponing childbirth, and eliminates religious and/or other ethical, legal, and moral concerns of embryo freezing ${ }^{5}$. Numerous individual studies investigating the different reproductive outcomes of cryopreservation on human embryos, immature or mature oocytes, or ovarian tissues have been reported. Currently, embryo and mature oocyte cryopreservation following IVF are the only methods endorsed by the American Society of Reproductive Medicine $(\mathrm{ASRM})^{6}$ and recommended by the American Society of Clinical Oncology (ASCO) for fertility preservation for patients with cancer?

Oocyte cryopreservation has improved dramatically in recent years and is receiving widespread clinical use. Novel approaches to further improve success, as well as improved methods to assess this success will aid in continued improvement ${ }^{1}$. Oocyte freezing confers thermal and chemical stress upon the oolemma and various other intracellular structures due to the formation of ice crystals. The lipid profiles of oocytes and embryos are closely associated with both, the degrees of their membrane fluidity, as well as the degree of chilling and freezing injuries that may occur during cryopreservation. Jaehun et al show that the identified phospholipids can be used as potential biomarkers of oocyte undergoing vitrification and will allow for the development of strategies to preserve phospholipids during oocyte cryopreservation ${ }^{8}$. However, we generally achieve better survival and pregnancy rates in vitrification compared to those of slow cooling/rapid thawing cryopreservation ${ }^{9}$. Vitrifications of mature oocytes and embryos obtained better clinical outcomes and did not increase the risks of DNA damage, spindle configuration, embryonic aneuploidy, and genomic imprinting as compared with fresh and slow-freezing procedures, respectively. Both embryo and oocyte vitrifications are safe applications in female fertility preservation ${ }^{10}$.

The patients with fresh TESA sperm and frozen PESA sperm showed significantly higher high-quality embryo rates than those of fresh ejaculated semen and fresh PESA sperm groups. The implantation rates with fresh TESA sperm and fresh PESA sperm were significantly higher than those of fresh ejaculated semen. The clinical pregnancy and live birth rates with fresh PESA sperm were significantly higher than those of fresh ejaculated semen group ${ }^{11}$. In our research, the couple with a history of unsuccessful ICSI cycles because of poor embryo quality achieve live birth by using donor sperm.Patients with oligozoospermia may benefit from ICSI treatment. However, some of infertile couples face poor results after ICSI and subsequently use artificial insemination with donor sperm. These couples with a history of unsuccessful ICSI cycles because of poor embryo quality are able to achieve high live birth rate after AID cycles ${ }^{12}$. Ghoraeian et al. ${ }^{13}$ demonstrated that men especially with severe oligozoospermia have an elevated risk for chromosome abnormalities in their spermatozoa. These abnormalities might affect fertilisation and pre-embryo formation with less impact on implantation.

In conclusion, to the best of our knowledge, this is a rare case of a successful delivery after transfer of vitrified-warmed embryo derived from ICSI with vitrified-warmed oocyte and frozen-thawed sperm after failed fresh ICSI cycle by using sperm of her husband in the same patient. However, further study on the safety of freezing, especially vitrification is needed.

\section{References}

1. Clark NA, Swain JE. Oocyte cryopreservation: searching for novel improvement strategies. J Assist Reprod Genet 2013; 30 (7): 865-75.

2. Ri-Cheng Chian, Yao Wang, Yi-Ran Li. Oocyte vitrification: advances, progress and future goals. J Assist Reprod Genet 2014; 31 (4): 411-20.

3. Noyes N, Labella PA, James Grifo J, Knopman JM. Oocyte cryopreservation: a feasible fertility preservation option for reproductive age cancer survivors. J Assist Reprod Genet 2010; 27 (8): 495-9. 
4. Yan D, Brown SE, Nguyen K, Reddy V, Brubaker C, Winslow KL. Live birth after the transfer of human embryos developed from cryopreserved oocytes harvested before cancer treatment. Fertil Steril 2007; 87 (6): 1469. e1-1469.e4.

5. Konc J, Kanyó K, Kriston R, Somoskői B, Cseh S. Cryopreservation of Embryos and Oocytes in Human Assisted Reproduction. Biomed Res Int 2014; 2014: 307268 .

6. The Practice Committees of American Society for Reproductive Medicine and the Society for Assisted Reproductive Technology. Mature oocyte cryopreservation: a guideline. Fertil Steril 2013; 99 (1): 37-43.

7. Munster PN. More Options for Fertility Preservation for Patients With Cancer. J Clin Oncol 2015; 33 (22): 2413-5.

8. Jung J, Shin H, Bang S, Mok HJ, Suh CS, Kim KP, et al. Analysis of the Phospholipid Profile of Metaphase II Mouse Oocytes Undergoing Vitrification. Plosone 2014; 9 (7): e102620.
9. Sarajari S, Manipalviram S, Surrey MW, Danzer HC, Briton-Jones C, Hil DL. Post-thaw survival and resumption of meiosis of immature oocytes using slow-freeze vs vitrification methods of cryopreservation. Fertil Steril 2007; 88 (6): S354-5.

10. Zhang L, Yan LY, Zhi X, Yan J, Qiao J. Female Fertility: Is it Safe to "Freeze?" Chin Med J 2015; 128 (3): 390-7.

11. Lin Y, Cai L, Dong J, Liu J, Chian R. Ejaculated sperm may not result in the best clinical outcome for ICSI treatment cycles. Fertil Steril 2015; 104 (3-Sup): e244.

12. Frapsauce C, Cornuau M, Splingart C, Barthelemy C, Royere D, Guerif F. Clinical outcome after insemination with donor sperm in patients with poor results in ICSI cycles. Andrologia 2013; 45 (2): 86-91.

13. Ghoraeian P, Mozdarani H, Aleyasin A. Alizadeh-Nili H. Frequency of sex chromosomal disomy in spermatozoa of normal and oligozoospermic Iranian patients and its effects on fertilisation and implantation rates after ICSI. Andrologia 2013; 45 (1): 46-55. 